\title{
TEXTOS Y PEDAGOGÍA EN LOS ALBORES DEL SIGLO XX EN COLOMBIA
}

\author{
Doris Lilia Torres Cruz \\ Universidad Pedagógica y Tecnológica de Colombia \\ Grupo de investigación HISULA \\ dorislilia6@yahoo.com \\ Carlos Arturo Londoño Ramos ${ }^{2}$ \\ Universidad Pedagógica y Tecnológica de Colombia \\ Grupo de investigación HISULA \\ londonocarlosarturo@,botmail.com
}

Recepción: 27/04/2011

Evaluación: 09/05/2011

Aceptación: 22/06/2011

Artículo de Reflexión

\section{RESUMEN}

En las tres primeras décadas del siglo XX, los textos escolares se utilizaron para promover proyectos políticos, ideológicos y pedagógicos. Sobre los textos escolares elementales de enseñanza del lenguaje, particularmente, se investigan las disposiciones jurídicas en cuanto tiene que ver con la normatividad educativa, los ideales, los principios, los métodos y las prácticas de enseñanza. Igualmente, se reconoce en los textos escolares las luchas en torno a las ideologías que propugnan por la manera en que se debe formar a los ciudadanos y en las orientaciones para construir un tipo de Nación.

Palabras claves: Revista Historia de la Educación Latinoamericana, textos escolares, escuela elemental, política educativa.

${ }^{1}$ Licenciada en Idiomas Modernos, Magíster en Lingüística y Doctora en Ciencias de la Educación - RUDECOLOMBIA, directora de posgrados de educación de la Universidad Pedagógica y Tecnológica de Colombia e integrante del grupo de investigación Historia y Prospectiva de la Universidad Latinoamericana HISULA y Lenguajes en Educación Leen.

${ }^{2}$ Doctor en Filosofía de la Universidad Javeriana, profesor de la Universidad Pedagógica y Tecnológica de Colombia e integrante del grupo de investigación Historia y Prospectiva de la Universidad Latinoamericana HISULA. 


\title{
TEXTBOOKS AND PEDAGOGY IN THE BEGININGS OF THE XXTH CENTURY, IN COLOMBIA
}

\author{
Doris Lilia Torres Cruz \\ Universidad Pedagógica y Tecnológica de Colombia \\ Research Group HISULA \\ dorislilia6@yahoo.com \\ Carlos Arturo Londoño Ramos \\ Universidad Pedagógica y Tecnológica de Colombia \\ Research Group HISULA \\ londonocarlosarturo@,hotmail.com
}

\begin{abstract}
In the first three decades of the 20th century, the school textbooks were in in order to promote political, ideological and pedagogic projects. On the elementary school texts of education of the language, particularly, the juridical regulations are investigated in all that it has to see with the educational normativity, the ideal ones, the principles, the methods and the practices of education. Likewise, the fights are recognized in the school texts concerning the ideologies that they support for the way in which it is necessary to train the citizens and in the guidelines to construct a type of Nation.
\end{abstract}

Key words: Journal of Latin American Education History, scholar texbooks, elementary school, educational policies. 


\title{
TEXTOS E PEDAGOGIA NOS ALVORES DO SÉCULO XX NA COLÔMBIA
}

\author{
Doris Lilia Torres Cruz \\ Universidade Pedagógica e Tecnológica da Colômbia \\ Grupo de pesquisa- HISULA \\ dorislilia6@yahoo.com \\ Carlos Arturo Londoño Ramos \\ Universidade Pedagógica e Tecnológica da Colômbia \\ Grupo de pesquisa-HISULA \\ londonocarlosarturo@hotmail.com
}

\section{RESUMO}

Nas três primeiras décadas do século XX, os textos escolares foram utilizaram para promover projetos políticos, ideológicos e pedagógicos. Sobre os textos escolares elementares de ensino da linguagem, particularmente, se pesquisam as disposições jurídicas enquanto possuem relação com a normatividade educativa, os ideais, os princípios, os métodos e as práticas de ensino. Igualmente, se reconhece nos textos escolares as lutas em torno das ideologias que propunham a maneira pela qual se deve formar aos cidadãos e nas orientações para construir um tipo de Nação.

Palavras - chave: Revista História da Educação Latino-americana, textos escolares, escola elementar, política educativa. 


\section{INTRODUCCIÓN}

En Colombia, las políticas educativas de las tres primeras décadas del siglo XX, dividieron la instrucción pública en primaria, secundaria, industrial y profesional. La primaria fue promovida obligatoriamente por los gobiernos departamentales. La práctica y no la teoría fue el principio que se promulgó en toda la legislación, así mismo, las nociones elementales que iniciaban a la catequización, habilitaban para el ejercicio de la ciudadanía y preparaban para el trabajo.

La Ley 39 de 1903, tenía por misión la educación cristiana de los niños, la cual se hacía obligatoria en todos los grados y niveles, tanto que debían confesar personalmente su creencia, participar en el culto y recitar las oraciones al pie de la letra. La Ley propuesta por el Ministro de Instrucción Pública, Antonio José Uribe, exigía la práctica, la confesionalidad religiosa y la homogeneidad nacional. En concordancia, el Decreto Reglamentario 491 de 1904 (capítulo IV, Art. 5) promovía la Junta de Inspección, en la cual, era primordial la presencia del cura párroco en el municipio respectivo; quien definía el nivel de cada niño y el reconocimiento como un sujeto admitido dentro de la escuela.

La Nación inspeccionaba la educación secundaria, la industrial y profesional. La instrucción primaria quedaba definida como "esencialmente práctica" y orientaba a dotar al alumno de las "nociones elementales que lo habilitaban para el ejercicio de la ciudadanía y lo preparaban para la agricultura, la industria y el comercio" ${ }^{3}$. La secundaria fue, a su vez, especializada en técnica (materias profesionales) y clásica (cultura general, idiomas, filosofía y letras) aunque se recomendaba fomentar prioritariamente la instrucción técnica. La entidad encargada de la enseñanza industrial y comercial, se debía preocupar por la fundación de escuelas de artes y oficios donde se adiestrarían los estudiantes en la manufactura y "en el manejo de máquinas aplicables a las pequeñas industrias".

En el centro de los decretos reglamentarios se encontraba en la escuela elemental, que se clasificó en rural y urbana y precisó diversos tópicos tales como la catequización de indígenas, el sostenimiento de las escuelas, el número de niños permisibles en cada una de ellas, la edad

3 COLOMBIA. MINISTERIO DE EDUCACIÓN. Educación Colombiana: 1903-

1958. Bogotá, Imprenta Nacional, 1959, p. 9.

Ibídem., p. 10. 
escolar y el plan de estudios. Según este Decreto, la enseñanza primaria debía integrar la educación moral, cuyo fin "era la práctica de los deberes para con Dios, para consigo mismo, para con los padres y superiores, para con los semejantes y para con la patria"; con la educación intelectual, "que desarrollaba en el niño el conjunto de facultades mentales"; y con la educación cívica y física. Basado en estas orientaciones, se definió el plan de estudios de la primaria diferenciando la escuela rural de la urbana, el pénsum para niños y para niñas, y las materias para cada nivel.

La escuela rural constaría en adelante de un ciclo de tres años, y la urbana por uno de seis años dividido en tres niveles: elemental, medio y superior. Las diferencias curriculares entre la escuela rural y urbana se ilustran en las asignaturas estipuladas para el primer año: en la rural, el niño aprendía religión, lectura, escritura, aritmética y urbanidad; junto con las anteriores, la urbana agregaba dibujo lineal, canto, lecciones objetivas, trabajos manuales ("obras de mano") y calistenia (como se denominaba a la gimnasia).

El Decreto legisló también sobre los textos. Estableció que éstos debían ser aprobados por una junta de pedagogos y por el Arzobispo de Bogotá; quienes a su vez, también determinaban y definían los deberes de los maestros, los requisitos de la matrícula y asistencia, los exámenes y el sistema correccional. Todo lo anterior basado en el principio de la pedagogía y la moral católica, apostólica y romana ${ }^{6}$.

Una parte significativa se puede encontrar en el capítulo VIII del Decreto 491 de 1904 con respecto a los textos y programas, donde se advierte que la instrucción primaria debía ser uniforme en toda la República, con características nacionales y con el cubrimiento de todas las necesidades y conveniencias de la misma. Los textos eran designados por el Gobierno, quien para ello hacía que una Junta de pedagogos distinguidos que conformaran los programas de la enseñanza en las escuelas y los aprobaran para ser publicados en el Diario Oficial, a fin de que, dentro del plazo que se señalara, se presentara al Ministerio de Instrucción Pública los textos aprobados. Así mismo, los textos que se elegían para la enseñanza de materias morales y religiosas deberían ser aprobados previamente por el Ilmo. Sr. Arzobispo de Bogotá, con arreglo

\footnotetext{
${ }^{5}$ Ibídem., p. 26.

CONCORDATO DE 1887, art. 11, 12, 13,14. Constitución Política de Colombia 1886 , art 41.
} 
al Concordato en el que se estipulaba la obligatoriedad de la educación religiosa confesional.

En relación con la instrucción secundaria, la reglamentación de 1904 fue menos amplia, e hizo referencia básicamente a los planes de estudio de las escuelas normales, de la instrucción técnica y de la clásica, así como a la fundación de la Revista de Instrucción Pública. Las escuelas normales tenían como objeto la formación de maestros de primaria y deberían existir en cada departamento, siendo la Escuela Normal de Cundinamarca la encargada de formar el personal docente para todas las otras Normales. El conjunto de materias del plan estaba orientado "a la adquisición de nociones suficientes no sólo en el orden moral e intelectual sino también en los principios aplicables a la industria, la agricultura y el comercio" La instrucción técnica comprendía materias vinculadas con las ciencias naturales y con las matemáticas guiadas por el "método empírico". La secundaria clásica por el contrario, poseía una orientación más teórica y clásica. Vista en su conjunto, la reforma fue una expresión directa de los fundamentos constitucionales formulados por Núñez y Caro, donde predominaban tres elementos: la unidad nacional, la preeminencia de la Religión católica y el "fomento de la riqueza".

Ciertamente, la ley 39 de 1903 tenía el antecedente inmediato del Plan Zerda de 1892, pero el Ministro Uribe fue más contundente al lograr una mayor planificación del proyecto anterior ${ }^{10}$, mediante la reorganización del Ministerio de Instrucción Pública. La ley hizo una definición rigurosa de las funciones directivas $\mathrm{y}_{1}$ administrativas del ejecutivo y de la diversidad de los niveles educativos . Sobre todo, al proponer la ley, se plasmaba proyecto hegemónico que el conservatismo había formulado como consecuencia del triunfo en la Guerra de los Mil Días ${ }^{12}$. Después de la guerra, la hegemonía conservadora se hacía posible con la derrota del liberalismo. Unidad hispano-católica, centralización e intervencionismo eran los ejes sobre los cuales giraba el proyecto político conservador a comienzos del siglo XX.

7 DIARIO OFICIAL 12.122. Decreto número 491 de 1904 (3 de junio). Jueves 14 de julio de 1904.

${ }_{9}^{8}$ Ibídem., p. 27.

JARAMILLO URIBE. (1980): Manual de Historia de Colombia: el proceso de educación. Bogotá, Colcultura, p. 280.

${ }_{11}^{10}$ Ibídem, p. 280.

${ }^{11}$ DIARIO OFICIAL 12.122. DECRETO 491 de 1904, art. 1 al 5 de la Ley 39 de 1903, óp., cit, p. 17.

MELO, Jorge Orlando. (1978): "La república conservadora", en: Colombia Hoy. Bogotá, Siglo XXI, p. 35. 
La unificación de la Nación y del Estado no dependía solamente de la centralización política, era también un problema de unidad espiritual, ideológica y lingüística. La Iglesia católica como poder real, centralizado, jerarquizado y como doctrina unitaria, profundamente arraigada en el pueblo colombiano, posibilitaba el proyecto de unidad nacional. La amplitud y solidez del aparato burocrático de la Iglesia y la legitimidad y aceptación de su autoridad eran elementos indispensables para el proyecto político conservador.

Así mismo, los Inspectores procuraban que la educación en las escuelas fomentara la enseñanza y la educación en la niñez, señalando las materias principales que, atendiendo a las circunstancias de los pueblos, deberían enseñarse de preferencia y por mayor necesidad, como fueron: el catecismo (Religión y moral), explicado con mayor o menor amplitud según la edad y el estado de instrucción de los niños; leer, escribir y contar, con la mayor perfección que se podía en cada año o curso escolar, añadiendo poco a poco materias prácticas de acuerdo con el nivel del niño ${ }^{13}$. De estas materias se preferían las de enseñanza de la pequeña industria manual, cultivo de plantas que produjeran materias primas, agricultura, oficios manuales, ganadería y cría de animales. Esto implicaba dejar de lado la literatura y los conocimientos vagos, que por ser efímeros e inconexos, ningún provecho les podría traer . Para los niños indígenas o semiindios, fueron abiertas escuelas superiores, o colegios, tanto para niñas al cuidado especial de las Hermanas de la Caridad, como para niños bajo la dirección de los Hermanos Cristianos ${ }^{15}$.

De la escuela debía salir las vidas útiles, los talentos con orientación firme, los corazones generosos, los padres honrados, los obreros modelos, los ciudadanos sumisos, los magistrados puros, los artistas inspirados y los soldados intrépidos; de ella sacaban los medios de engrandecimiento. Se insistía a los padres usar más la autoridad que los sentimientos, pues

${ }^{13}$ BÁEZ OSORIO, Myriam. (2004): Las Escuelas Normales y el cambio educativo en los Estados Unidos de Colombia en el periodo Radical, 1870-1886. Tunja: Universidad Pedagógica y Tecnológica de Colombia, p. 28. Se hace un análisis detallado de los hechos que se dieron en el período Radical y la presión de la Iglesia por la institucionalización de la materia de religión en los planteles educativos; fueron muchísimas las posiciones que se presentaron relacionadas con la clase de religión en las escuelas, sin embargo al caer la Constitución de 1863 e implementarse la de 1886, se consolida el debate y se da el triunfo de un sector de los conservadores que se opusieron a la educación laica desde el año de 1870, cuando se expidió el Decreto orgánico de Instrucción Pública.

INTENDENCIA DEL META. Informe del Vicario Apostólico del Casanare, Inspector de Instrucción Pública en las escuelas de ese territorio de la Intendencia del Meta, en el primer semestre del año. Casanare: El autor, 1905, pp. 49 y 78.

Ibídem., p. 79. 
esta perduraba, los otros no. El buen maestro debía cumplir con unas condiciones de moral muy elevadas, dando ejemplo como lo dio Jesucristo, sembrando ideas y haciendo aceptar principios con convicciones profundas desde el orden físico, intelectual y moral. Sin embargo, tan buenas intenciones e ideales, se sacrificaban, y se preparaba la guerra, tan pronto aparecía el fantasma de la educación laica y el Estado no confesional. Se consideraba que cuando en ese recinto sacro de la escuela se falseaban las nociones, entonces eran instrumento móvil de decadencia y ruina. Los elementos de una buena educación eran: Dios, los padres, el maestro, el condiscípulo y el educando. Por lo tanto era horroroso pensar cuando en las escuelas era arrancado el crucifijo, cuya sola vista podía consolar, sostener y fortificar, y con él desaparecían todas las enseñanzas cristianas . Se decía que el crimen aumentaba y que las naciones como Francia se habían criminalizado por haber arrancado al Salvador de sus escuelas, lo que llevaba a tener franceses que no amaban su patria y eran antimilitaristas. Todo anterior es fruto de la escuela laica ${ }^{17}$.

\section{Los métodos y procedimientos de la enseñanza}

Los métodos de enseñanza se aplicaron y pusieron en práctica según la materia. El método dependía del asunto, de la clase de alumnos y del maestro mismo. El objeto del método era el de instruir con facilidad, mediante el dominio de los asuntos que se enseñaban. De este modo en la época, se proponían cinco métodos: el inductivo, el deductivo, el analítico, el interrogativo y el narrativo.

Los métodos de enseñanza que se promulgaron para ser aplicados en la primaria fueron: en primer lugar, el de Pestalozzi ${ }^{18}$, que era una

\footnotetext{
${ }^{16}$ Debido a que las relaciones Iglesia-Estado se encontraban deterioradas por las medidas de los gobiernos liberales radicales, el primer paso del gobierno regenerador fue normalizar esas relaciones, ya que según su filosofía la Religión Católica era un elemento esencial de orden social, capaz de lograr la unificación del País. Con este propósito el presidente Rafael Núñez celebró el 31 de diciembre un Concordato con la Sede Apostólica en Roma que fue sancionado por la ley 35 de 1887. Se le confía a la Iglesia una gran incidencia en la educación pública, que desde ese momento deberá ser organizada y dirigida por los dogmas y la moral de la Religión católica. Por último, el Concordato elimina el divorcio y le delega a la Iglesia el registro de nacimientos, matrimonios y defunciones.

GONZAGA, Luis. "Discurso pronunciado en la distribución de premios en la Escuela Normal Central de Institutores de Bogotá, el 29 de noviembre de 1913”, en: Revista de Instrucción Pública de Colombia. Bogotá, Órgano del Ministerio del Ramo. N. 1 y 2, T. XXVI (enero-febrero, 1913), p.738.

RESOLUCIÓN NÚMERO 134 del 19 de noviembre de 1906. Por la cual se aprueba el Decreto número 87 de 1906 para su aprobación enviado al Despacho del Gobernador del Departamento del Huila y donde se reglamentan las escuelas primarias. p. 674. Ibídem, p. 175.
} 
enseñanza inductiva que empleaba el denominado "método objetivo" o "intuitivo", puesto que procuraba partir de la evidencia primera: la experiencia, la acción, el interés en el aprendizaje práctico y el contacto con la naturaleza; así el método era apropiado en la enseñanza de la zoología, la botánica, las ciencias naturales, la escritura, la geografía, el dibujo y todo aquello que se pudiera representar o hacer sensible a los sentidos y que permitiera dar lecciones con los objetos a la vista o "lecciones de cosas."

El método deductivo o heurístico ${ }^{19}$ por el cual se enseñaba a pensar en las causas, en la búsqueda de explicaciones o leyes. Lo empleaba el institutor para que los discípulos descubrieran por sí mismos las verdades, principios y reglas que deseaba enseñar, mediante ciertos datos suministrados para encaminarlos a hallar la verdad. Este método era sin duda el mejor de todos, porque lo que el niño descubriría nunca lo olvidaría, porque se consideraba como inventor o propietario de la cosa descubierta, además mantenía la imaginación en actitud provechosa para crear ideas, combinarlas y dar así al hombre la gran cualidad de observar, reflexionar y deducir lógicamente las verdades científicas: distintivos de sabios y filósofos. Este método debía usarse para enseñar gramática en cualquier idioma, aritmética, geometría, física, etc.; el institutor debía ser conocedor del plan que se proponía y tener la suficiente paciencia para esperar las respuestas del niño. También se empleaban para proceder de lo general a lo particular o viceversa: algunos ejemplos de métodos eran iniciar los estudios gramaticales dando una regla explícita y confirmarla por medio de aplicaciones. O por el contrario, se principiaba por escribir varias frases, observar ciertas particularidades que le eran comunes y deducir una regla. En ambos casos se procedía metódicamente.

El método analítico se combinaba con el sintético ${ }^{20}$, que eran dos métodos complementarios, es decir, se servían recíprocamente de ambos, según la materia que se tratara de enseñar. El análisis o método analítico consistía en tomar el todo para descomponerlo en sus partes, anotando las propiedades de cada aspecto, es decir, del todo a lo simple. El método sintético era aquel por el cual se procedía de las partes al todo, es decir, cuando se estudiaban las partes una a una para formar un todo armónico, y también cuando se procedía de lo simple a lo compuesto. Los dos métodos se utilizaban para el repaso de la gramática, la geografía y ciencias naturales.

\footnotetext{
${ }^{20}$ Ibídem, p. 176.
} 
El método interrogativo o socrático, radicaba en una cadena de preguntas para promover la búsqueda de respuestas por parte del estudiante: para conducirlo a descubrir la verdad por sí mismo. El maestro lo estimulaba y dirigía haciendo que él expusiera sus propias ideas; si éstas eran correctas, el maestro las fijaba por medio de oportunos ejemplos; si eran erróneas, le hacía ver claro el absurdo para que el discípulo descubriera sus consecuencias. Este método se recomendaba para desarrollar la inteligencia, pues se debía dejar al alumno todo el trabajo de observación e investigación, en el cual sintiera el goce del descubrimiento por sí mismo. Requería una atención sostenida y fuerzas intelectuales desarrolladas; a este método también se le denominaba erotemático, puesto que se basaba en el amor al saber.

El método narrativo procuraba enseñar por medio de descripciones, discursos, cuentos, biografías, fábulas especialmente cuando se trataba de historia, religión, moral, vidas ilustres, composición y urbanidad. El método también se denominaba "acromático", pues su nombre viene de una voz griega que significaba oír para instruirse ${ }^{22}$. No obstante, había que tener mucho cuidado de no caer en el defecto y manía común entre los institutores, de adormecer a los niños con largas pero raciones y disertaciones fastidiosas, que narcotizaban la inteligencia y hacían caer al cuerpo en una especie de adormecimiento que enervaba hasta la vida. Para evitar esto, se debía hablar poco e interrogar inmediatamente con viveza sobre lo enseñado, o hacer que los niños escribieran un cuestionario o resumen de las lecciones. Este método se debía usar para enseñar a niños que tuvieran algún desarrollo intelectual y fueran capaces de entender el lenguaje del institutor ${ }^{23}$.

Con el uso de los métodos activos se proponía prohibir el método memorial, fundado en el ejercicio exclusivo y servil de la memoria. Esto no significaba que se excluyera el desarrollo de esta facultad en el niño,

\footnotetext{
${ }^{21}$ DE LA TORRE GÓMEZ, Andrés. "El método socrático y el modelo de van Hiele". Universidad de Antioquia, Medellín. En: Lecturas Matemáticas. (2003): Vol. 24, p. 99121. El método empleado por Sócrates consta de dos partes: destructiva una, creativa la otra. En la primera etapa, Sócrates toma como punto de partida la concepción del interlocutor acerca del asunto en cuestión, permitiéndole descubrir las contradicciones y las faltas de tal concepción. En la segunda etapa, llamada mayéutica, Sócrates se ve a sí mismo como una partera que ayuda a su interlocutor a dar a luz, a des-cubrir, a des-velar, la verdad que lleva en sí mismo, a quitarle a esta verdad el velo que la cubre. Es esencial al método el empleo sistemático de la ironía socrática, que consiste en simular ignorancia sobre la materia de que se trata, con el fin de hacer aparecer la verdad a través del diálogo entre el maestro y el aprendiz.

${ }_{23}^{22}$ RESOLUCIÓN NÚMERO 134 de 1906, óp., cit, p. 174.

Ibídem, p. 173.
} 
sino que se había de cultivar en combinación con el entendimiento, siguiendo el principio de Amos Conmenius, sabio pedagógico para quien: "Nada, absolutamente nada debe aprenderse de memoria antes de haber sido perfectamente comprendido". En ningún caso, el maestro podía pasar de una parte de la lección a otra, antes de que los niños hubieran comprendido bien las partes que se hubieran explicado. Sin embargo, al parecer, en el empleo de los métodos también se encuentran contradicciones, pues, mientras de una parte se insiste en la comprensión, de otra, el catecismo del Padre Astete y la historia, debían aprenderse simplemente de memoria. Esta situación muestra la gran distancia que se ha presentado entre las políticas educativas activas y la inercia de la tradición pedagógica.

Los métodos generales expuestos, eran suficientes y los debían emplear los maestros. Pero además, se debía hacer uso de otros expedientes llamados métodos auxiliares pero que propiamente eran procedimientos didácticos como el uso constante de la repetición, cuya importancia se recomendaba ${ }^{24}$.

Cualquiera que fuera el método ${ }^{25}$ adoptado se empleaba el procedimiento de efectuar muchos escritos; el tablero, la pizarra y el papel eran importantes auxiliares en la enseñanza y debían utilizárseles constantemente. También podía usarse el procedimiento de ejercicios en coro, por toda la clase o por secciones de ella, para las respuestas, la lectura y las recitaciones. Estos ejercicios, empleados con moderación, servían para dominar la timidez, para acostumbrar al alumno a leer con pausas y con la entonación conveniente, y para fijar en la memoria un hecho cualquiera; pero cuando se empleaba de ordinario y casi con exclusión de otros medios, las respuestas en coro aparentaban mucho por la uniformidad mecánica, pero valían poco para la enseñanza sólida.

No había que confundir el método con el procedimiento: el método en la enseñanza era el camino que seguía el espíritu, para exponer y hacer

\footnotetext{
${ }_{25}^{24}$ Ibídem., p. 178.

${ }^{25}$ REPÚBLICA DE COLOMBIA, MINISTERIO DE INSTRUCCIÓN PÚBLICA. Circular N. 1025, p. 9. Se planteaba que la educación debía ser conducida por ciertas reglas, de modo que fuera proporcionada, es decir, que no todas las enseñanzas son propias para la edad del niño; la educación debe ser sobria, para que no inflara la mente del niño con múltiples y vagos conocimientos: importaba sobre manera huir del enciclopedismo, más pernicioso que la ignorancia; debe ser metódica, proceder con orden desde los primeros principios a las más abstrusas consecuencias. También debe ser adecuada, con la finalidad de servir para el desarrollo de las diversas facultades, entre ellas, la memoria, se debía cultivar como el más precioso instrumento pedagógico, como el más útil a todas las facultades del hombre.
} 
comprender la verdad de lo que le enseñaban; el procedimiento era el medio práctico que empleaba el método para alcanzar su objetivo. Leer una frase y hacer escribir en las pizarras palabras que por las relaciones que guardaban entre sí o que contenían la regla que se pretendía aplicar y retener, y después presentar las pizarras y examinar si se había escrito bien o mal, es otro procedimiento. Valerse de una caja de letras para enseñar la lectura, de un tablero o de un ábaco para enseñar a contar, es otro procedimiento. Se recomendaba a los maestros, que sin haber hecho estudios especiales, fueran muy estudiosos y procuraran tener consigo los tratados de los autores modernos sobre pedagogía y metodología, a fin de que sus conferencias se ajustaran en lo posible a sus doctrinas, pues de otro modo no podían ser satisfactorios los resultados de la escuela, por más erudición que hubiera en el maestro.

\section{Los textos escolares de lectura y su metodología}

El libro de texto, como la historia del libro, según Lucien Febvre, se debe ver de manera global, como un problema de historia a la vez técnico y económico, pero también social, intelectual, cultural, simbólico y artístico; así resulta ser un producto con un conjunto de estructuras y redes que están en el origen, pero también como un objeto que servirá de soporte a una multitud de prácticas más o menos complejas. Por lo tanto, el mundo del texto nos llevará a leer lo textual, lo paratextual y lo icónico; es decir, a tratar de conocerlo con aquello que da el texto a leer y con lo que da a leer sin ser texto: los títulos que circulan, los sistemas de referencia (paginación, foliación, tablas, índices, etc.), la lógica de los párrafos, el juego de las mayúsculas, de los espacios, las imágenes, entre otros; todo lo que puede hacerse sobre los renglones con el fin de intentar elucidar las relaciones entre el texto y los sistemas dominantes de pensamiento en una época determinada. Así las tipologías propuestas para clasificar los textos y su contenido condiciona sus posibles lecturas, determinadas también por técnicas apropiadas de difusión.

El trabajo sobre los textos nos permitirá reconocer el dominio de lo escrito y de los sistemas de comunicación como elementos esenciales en las relaciones de poder, en la afirmación de unas políticas o en la imposición de unas formas de pensar ideológicas o de unas estructuras categoriales

${ }^{26}$ FEBVRE, Lucien y MARTIN, Henri Jean. (2005): La aparición del libro. México, FCE, p. 421. 
en defensa de instituciones político-religiosas ${ }^{27}$. Este punto de vista lleva a establecer tipologías, niveles de cultura y de su articulación con prácticas educativas. Desde esta perspectiva, los textos escolares son espacios para procurar la construcción de la Nación desde una perspectiva discursiva.

En los textos de la escuela elemental investigados ${ }^{28}$ se pudieron establecer unas frecuencias lingüísticas en cuatro categorías básicas, tales como son: el progreso, el conocimiento, la religión y lo social. Así cada categoría asumió indicadores de exposición de manifestaciones lingüísticas de la siguiente forma: en la categoría de progreso se incluyeron las referencias a la ciencia, el estudio, las máquinas y los aparatos; en la categoría de conocimiento se abarcaron los temas comprendidos en el universo, los animales, los vegetales, los minerales, los objetos útiles, el tiempo matemático, lo mitológico y la fábula; en la categoría de religión se comprendieron la iglesia, las celebraciones, las oraciones, el creacionismo, Dios, la Virgen María y los santos; y en la categoría de lo social se incluyen los asuntos referidos a la nación, la educación, la familia, la moral, higiene, roles, mujeres, hombres, niños, indios ${ }^{29}$. Uno de los textos más antiguos que data de fines del Siglo XIX y de orientación pestalozziana es el de Cartillas Objetivas para enseñar a leery escribir del autor César Baquero.

Los libros de G. M. BRUÑO fueron los textos utilizados en el País por varias generaciones de estudiantes. El seudónimo de G. M. Bruño corresponde a un Hermano lasallista denominado Francisco Febres Cordero, de origen ecuatoriano y quien se dedicó a escribir textos para los niños. ${ }^{31}$ Entre algunos texto que se destacan están: Lecciones elementales

${ }^{27}$ Cfr. LONDOÑO RAMOS, Carlos Arturo. (1985): "El discurso reactivo de la enseñanza escolar de la filosofía”, en: Rev. Educación y Ciencia. Quinta época, año I, Tunja: Universidad Pedagógica y Tecnológica de Colombia. Cfr. LONDOÑO RAMOS, Carlos Arturo. (1986): "Violencia simbólica y filosofía escolar." (1945-1970). En: II Simposio nacional sobre la violencia en Colombia. Bogotá: ICFES-UPTC.

${ }^{28}$ TORRES CRUZ, Doris Lilia. Política educativa y enseñanza de la lengua castellana en la educación elemental en Colombia en las tres primeras décadas del siglo XX". Doctorado en Ciencias de la Educación, Universidad Pedagógica y Tecnológica de Colombia. RUDECOLOMBIA. Tesis doctoral, 2010.

Sobre los textos escolares se ha tomado una muestra de 556 imágenes, con las cuales se manejaron 31 criterios para un total de 17.236 ítems trabajados.

CARDOSO ERLAM, Néstor Roberto. (2007): Los textos escolares en Colombia: dispositivos ideológicos, 1870-1931. Ibagué: Universidad del Tolima. Cfr. CARDOSO ERLAM, Néstor Roberto. (2001): Los textos de lectura en Colombia: aproximación histórica e ideológica, 1872-1917. En: Revista Educación y cultura, N. 29-30, Vol. XIII (ene-sep). Medellín, Universidad de Antioquia, p. 136.

BAQUERO, César. (1880): Cartilla Objetiva para enseñar a leer y escribir. Bogotá, Imprenta de la Luz. Segunda edición,

${ }^{1}$ Fue conocido en la orden como el Hermano Miguel y canonizado por el Papa Juan Pablo II, en 1984. Vivió desde 1854 hasta 1910. Tiene afinidades familiares con Tulio Febres Cordero en Venezuela. 
de geometría aplicadas al dibujo lineal, Geometría y trigonometría, Historia sagrada: antiguo y nuevo testamento, La gramatiquilla infantil, La ortografía al dictado, El silabario de lectura y la Aritmética, entre otros.

Silabario de Lectura: curso preparatorio ${ }^{32}$ de G. M. Bruño, publicado en 1887, hace un énfasis en la mayor frecuencia en la referencia a objetos útiles, seguida por la religión y, por último, el aspecto social. Lo cual se corresponde con la ideología del autor y su formación religiosa y lasallista. Aunque el texto en sí mismo, es escaso en mostrar imágenes amplias, se concentra en las letras, luego en la combinación en sílabas, para pasar a la formación de palabras y finalizar con frases. Muestra los dos tipos de caligrafía tanto la imprenta como la cursiva. Así mismo, recomienda al maestro que haga uso de los grabados en cuanto a preguntar por ellos a los niños. Éstos describían las figuras y las pronunciaban lentamente; de tal manera, que al pronunciar las palabras el maestro debía hacer notar al niño y llamar la atención entre la diferencia que había entre pronunciar y por ejemplo. Luego de este ejercicio, hacía que los niños escribieran las vocales y luego su combinación con la consonante $p$ o $m$. Un alumno escribía en el tablero primero cada una de la letras aisladas y luego le anteponía las vocales, los otros niños hacían lo propio en sus pizarras; escribiendo varias veces las sílaba y las palabras y así sucesivamente.

El texto El escolar Hispanoamericano ${ }^{33}$ de 1907, de las autoras Eva Gooding de Cárdenas y Paulina Gooding, fue un texto dedicado "En Homenaje de respeto de este libro al Primer Magistrado de la República Excelentísimo Señor General Don Rafael Reyes, fundador de la paz nacional y de la Instrucción de las clases obreras en Colombia”. El texto contaba, además con la aprobación eclesiástica, dado que esta obra estaba exenta de errores teológicos y morales y merecía la recomendación por el espíritu religioso que la inspira.

La metodología que propuso esta cartilla fue la de dejar atrás los métodos deductivos que procedían de la teoría a la práctica y el ejercicio mecánico que apuntaba a la memoria antes que la comprensión. En la página dedicada "A los maestros", promueve el método inductivo que procede de la práctica a la teoría, y de la investigación experimental antes que las abstracciones. Se decía que el punto de partida era lo objetivo,

\footnotetext{
${ }^{32}$ BRUÑO, G.M. (1887): Silabario de Lectura: curso preparatorio. Lima, Procuraduría General de los Hermanos cristianos.

GOODING DE CÁRDENAS, Eva y GOODING, Paulina. (1907): El Escolar

Hispanoamericano. Bogotá, Tipografía de Aranza.
} 
de tal manera que toda idea debía ser inmediatamente comprendida en la experiencia con el fin de cimentar después la teoría sobre los hechos conocidos, y ejercitar así de modo racional la memoria y demás facultades intelectuales. Con el método inductivo se esperaba la transmisión de conocimientos adecuados a los inicios de la inteligencia humana y el fundamento del progreso moderno. Lo abstracto sin la experiencia, quedaba por fuera de la enseñanza, especialmente lo relacionado con la lectura. A su vez, se manifiestan contra el predominio el método anticuado del deletreo, el del mero "sonideo" de letras o sílabas, o de alguno más adelantado de enunciación de palabras pero que desatiende el significado completo: sin relación alguna con la comprensión del sentido. El conocimiento mecánico del alfabeto, en sus vocales y consonantes, y en sus combinaciones dejaban a los niños a oscuras. De las palabras, de sus sílabas y de sus letras, es decir, en los métodos en los que se atendía más a la forma que al significado objetivo, no podía haber comprensión. El recargo de la memoria y aniquilamiento de la comprensión, representaba un nocivo predominio de la forma sobre la idea, por esta razón, produce el sonsonete o la mala entonación de la lectura.

${ }_{35}^{\text {Libro de Lectura }}{ }^{34}$, N. 1, 2, 3, publicado en 1914 por Luis Felipe Mantilla es de considerable importancia, dado que fue un texto utilizado a finales del siglo XIX y comienzos del XX. Todas sus publicaciones están dirigidas a los niños de Hispanoamérica. El autor, como miembro de La Real Academia Española de la Lengua, procura la pureza del lenguaje y se preocupó por cuidar del buen hablar, escribir y leer. El Libro de lectura N. $2^{36}$, en su nueva edición, es enteramente refundido con arreglo a la última ortografía de la academia española y está adornado con 22 grabados negros. El Libro de Lectura, N. 3, se propuso adoptar el uso del método simultáneo de lectura y escritura, continúa con los parámetros planteados por Mantilla y refleja que la categoría social es más frecuente que la de progreso, el conocimiento y la religión. Cabe señalar que la figura masculina se destaca entre los niños y las mujeres. Que en la categoría de religión aparece la figura de la Iglesia unida a la de Dios; así mismo, emplea la fábula como un recurso literario para exponer moralejas que son fuentes permanentes de cohesión y coerción social.

\footnotetext{
${ }^{34}$ MANTILLA, Luís F. (1914): Libro de Lectura 1, 2, 3. París, México, Librería de la Vda. de Ch. Bouret.

${ }^{35}$ Luís Felipe Mantilla fue profesor de lengua y literatura española en La Habana y en la Universidad de Nueva York. Fue miembro de la Real Academia Española de la Lengua. MANTILLA, Luis Felipe. (1910): Libro de lectura, N. 2. París, Librería de la Viuda de $\mathrm{CH}$. Bouret.
} 
El texto proyectó a la Nación como una visión homogénea y occidentalizada orientada hacia el mercado internacional, el progreso, el avance de la ciencia, donde los emigrantes blancos y la inversión extranjera eran componentes claves del desarrollo del país. En cuanto a la lectura, discutió la pertinencia de evitar el abuso de la memoria y de dar prioridad al aprendizaje estimulando por la observación o por la experiencia utilizando materiales como las lecciones de cosas, además del dibujo, el canto, la gimnasia y el trabajo manual.

A principios del Siglo XX, se forma la preocupación por la higiene de la lectura. En una nota preliminar se aclara cómo los textos modernos de enseñanza presentaban tanto inmensas ventajas como graves inconvenientes. Uno de los más importantes era producir en los niños la miopía, la cual se daba por la luz defectuosa de las escuelas o el uso de libros impresos en letras demasiado pequeñas o en tipos de papeles oscuros, unida a la posición defectuosa del cuerpo cuando se leía, se escribía, se estudiaba o dibujaba. Tan cierto era que los gobiernos nacionales, donde más generalizada estaba la enseñanza primaria, como Alemania, Francia y Suiza, habían llegado a preocuparse del caso, sobre todo los alemanes porque los tipos góticos tenían más desventajas que los latinos. Queriendo evitar esta situación, Mantilla usa caracteres claros, nítidos y en papel un tanto amarillento, que era el apropiado para la buena visión, pues no se presentaba un contraste demasiado vivo con el blanco, lo cual hacía que las letras se destacaran bien y facilitara la lectura sin ningún daño a la visión.

Es necesario destacar que el libro de lectura El Lector Colombiano, de la escritora Constanza Sanín de Díaz y Carmen Sanín Herrán, ganadoras del concurso abierto por el gobierno y adoptado como texto oficial en 1913, fue un texto utilizado para quienes ya tenían nociones elementales de lectura. Este libro siguió tanto el método inductivo, tanto como la forma gradual y progresiva, integrada a un método global: une algunas expresiones de estudio gramatical de la lengua, a los conceptos religiosos, morales, de geografía, historia, artes, instrucción cívica, ciencias naturales, paisajes históricos y selecciones poéticas.

Así mismo, la cartilla Citolegia colombiana ${ }^{38}$ de métodos combinados de Martín Restrepo Mejía, fue acogida a finales de la década de los años

${ }^{37}$ SANÍN DÍAZ, Constanza y SANÍN HERRÁN, Carmen. (1913): El lector colombiano: libro de lectura ideológica para el uso de las escuelas de la República. Bogotá, (s.e).

${ }^{38}$ RESTREPO MEJÍA, Martín. (1912): Citolegía colombiana. Bogotá, imprenta eléctrica. 
20, representando la escuela republicana a través de los símbolos de la bandera y la cruz. Justo V. Charry, como institutor graduado, escribe el texto titulado Enseñanza simultánea, libro 1 de lectura y escritura, publicado en 1917 y actualizado por Cecilia Charry Lara en 1968. Utiliza en el texto la combinación de los métodos del silabeo y fonético según el sistema pestalozziano.

Esta cartilla presenta las indicaciones para la enseñanza de la lectura y escritura simultáneamente. Al enseñar a escribir una letra debía darse el sonido y no el nombre de ésta. Por lo tanto, la cartilla da a conocer y describe la forma adecuada de cada uno de los sonidos de las letras del alfabeto. Por ejemplo: con ambos labios $b, m$, $p$; con el labio inferior y los dientes superiores $v, w$, f; con la garganta $c, g, j, k, q$, $x$, etc. Así para enseñar una consonante se daba la sílaba como se indicaba en la lección modelo, y para enseñarla a escribir se daba el sonido. La pizarra debía llenarse por una de las caras con la lección del día, y por la otra, con ejercicios de escritura, conforme a la muestra que iba en cada lección.

El maestro debía observar la higiene en la escritura, y así, tener en cuenta todas las advertencias que hacía la cartilla sobre el modo de escribir desde el primer día. La ubicación de la pizarra, la cual se colocaba sobre la banca o mesa con una inclinación de 45 grados más o menos, contados desde el borde inferior de la banca; la luz debía entrar desde el lado izquierdo para no dañar la vista; la altura de banca debía ser proporcionada al cuerpo del niño y las manos debían formar un ángulo recto sobre la pizarra. Todos los ejercicios apuntaban a reconocer los movimientos caligráficos desde la técnica corporal, más que la comprensión. Así en un comienzo se buscó como objeto de la escritura desarrollar los músculos para "soltar la mano" en relación con la inclinación de las letras. Para realizar estos ejercicios. el movimiento debía partir no de las muñecas, sino del codo; pues estos no tenían por objeto escribir sino practicar el movimiento con que luego se escribiría. Así, el brazo no debía deslizarse con manga sobre la mesa, sino simplemente describir en una y otra dirección, un círculo tan grande como la flojedad de los músculos lo permitieran.

Un texto de considerable relevancia no sólo por su gran difusión en el tiempo y en el espacio sino porque además presenta en su carátula

\footnotetext{
${ }^{39}$ CHARRY, Justo V. (1917): Enseñanza Simultánea de Lectura y Escritura: Libro 1 y Libro
} 2. Bogotá, editorial Voluntad (Para la edición de 1949). 
símbolos de la Pedagogía activa, es la Cartilla Alegría de Leer, grado primero y cuarto, de la autoría del Médico Quintana Evangelista Rentería, escrito en 1930. Fue el primer best seller de las letras colombianas, con un tiraje de más de un millón de ejemplares ${ }^{41}$ La cartilla refleja en buena medida la última década de la hegemonía conservadora y el comienzo del proceso liberal que defiende el pensamiento de la nueva pedagogía.

En el texto, cada lección estaba acompañada de dibujos con la técnica del grabado cuyo contenido hacía referencia al tema de la lección, acompañada de ejercicios de lectura. Se van utilizando los grabados para la descripción de las imágenes. Sucesivamente, aumentan las sílabas, para que el niño pudiera pronunciarlas adecuadamente y mejorara su dicción, a la par que construía palabras y sonidos con sentidos. Las lecturas graduadas recreaban e informaban sobre el saber, la moral, la instrucción cívica, las lecciones de cosas, la geografía y la historia. En cuanto a las categorías de frecuencia lingüística de los términos, predominan las personas, especialmente, las figuras masculinas, seguidas por las figuras de los niños, junto con el de las mujeres.

La higiene de la escritura se articulaba con el sistema de la táctica escolar y todo el movimiento biopolítico de la época por la medicalización y la purificación de la raza. Por táctica escolar se entendía el conjunto de señas y movimientos adecuados para hacer que los niños desde el principio cumplieran con las tareas de la escuela. Una buena táctica ahorraba tiempo, comunicaba fuerzas, hacía agradable el trabajo, avivaba la clase y acostumbraba a obedecer estrictamente. Así como el orden era el resultado de un buen sistema, la falta de este o un sistema inadecuado para los movimientos de los alumnos ocasionaba confusión y desorden ${ }^{42}$.

Este método del "silabeo" en el que predomina la letra sobre la frase sigue la pedagogía de Pestalozzi, como precursor de la pedagogía activa para quien los métodos pedagógicos deben partir de lo simple a

\footnotetext{
${ }^{40}$ EVANGELISTA RENTERÍA, Quintana. (1930): Alegría de leer: grado primero. Bogotá, Editorial Voluntad, 38 edición, 1930.

El médico Evangelista Quintana Rentería, nacido en el Valle del Cauca. De su vida, se conoce que estuvo en París en 1928 en el VII Congreso Internacional de la Infancia y que en 1839 también fue a Buenos Aires como delegado al Primer Congreso Americano de Amigos de la Infancia. Todos los libros de la serie fueron hechos a cuatro manos, con la colaboración de su esposa Susana de Quintana, quien era maestra graduada y especializada en Chile.

Revista de Instrucción Pública de Colombia. (1906): Periódico oficial destinado al fomento y a la estadística de los establecimientos de enseñanza primaria. No. 12, p. 696.
} 
lo complejo. La escuela pestalozziana es promovida en el País por las misiones alemanas. Los nuevos cambios pedagógicos se generan con Agustín Nieto Caballero por la creación del Gimnasio Moderno 1914 con el fin de aplicar las ideas de la pedagogía activa. Así se retoma el impacto generado por la nueva pedagogía a raíz de los estudios realizados por Nieto Caballero con Claparéde en Suiza, la promoción de la Escuela Nueva por parte de Ferriére en Chile, la visita de Dewey a México, las conferencias de Decroly en España, Bolivia y Colombia. Todo el movimiento de la pedagogía activa en el mundo hispánico, se centra en la Revista de Pedagogía, fundada en Madrid en 1922 y en las traducciones de Lorenzo Luzurriaga, no obstante, el impulso de las nuevas corrientes pedagógicas fue destruido en 1936 por la Guerra civil española, como también lo fue en Colombia a partir de la violencia de $1946^{43}$.

A partir de Decroly, quien retoma la sicología de la gestalt, el conocimiento espontáneo procede del todo a las partes y en este sentido, procede del análisis a la síntesis. El lenguaje se aprende desde el contexto de sentido global, a la frase, y después, a la sílaba y la letra. Esta pedagogía utiliza un método global a través de los centros de interés en los que los niños realizan proyectos en los cuales practican las matemáticas, la lectura, la escritura, la expresión oral y utilizan los métodos de la ciencia aplicados a la pedagogía, es decir, emplean la relación entre inducción y deducción, el análisis y la síntesis y, las diferencias y las semejanzas. La pedagogía activa, en general, se preocupa por la relación teórico-práctica, por el método de proyectos y por la vinculación de la escuela y la sociedad. Esta nueva orientación produce una presión para cambiar los métodos del silabeo por un lenguaje articulado con significación práctica y social.

La ideología conservadora a favor de una propuesta hispanista, de nacionalismo unitario y catolicismo, contrastaba con la defensa liberal de la ilustración, el laicismo en el Estado y en la educación, la descentralización y la pedagogía activa. Sin embargo, el problema es más complejo,

\footnotetext{
${ }^{43}$ LONDOÑO RAMOS, Carlos Arturo. (2004): "La educación en la democracia integral: el constructivismo práctico de John Dewey y el impacto pedagógico de la Escuela Nueva durante la República liberal en Colombia", en Revista Cuestiones de filosofía. N. 6. Tunja, UPTC.

Por la hegemonía que pretendían los conservadores, no es de extrañar, por lo tanto, que en 1886 se fundara el Externado de Derecho y Ciencias Políticas, cuyo lema fue: "Post tenebra, spero lumem" (Después de las tinieblas espero la luz). Aunque la Universidad se clausuró en 1895 se volvió abrir en 1918. Así mismo, en 1890 se fundó la Universidad Republicana, la cual fue cerrada y vuelta a abrir en 1903, para ser clausurada definitivamente en 1917. De esta nació la Universidad Libre en 1913.
} 
pues mientras todos los partidos están de acuerdo con la renovación educativa y por lo tanto con los métodos activos de la pedagogía y su orientación hacia el trabajo, los conservadores no aceptan las políticas de la educación mixta, el laicismo, la universalidad de la educación pública y la filosofía del constructivismo pragmático implícita en la pedagogía de la Escuela Nueva. Los conservadores defendían la filosofía medieval escolástica "contemplativa" y el contubernio Iglesia-Estado. Por estas razones la Iglesia prohibió el libro $\underset{45}{E}$ lDr. Decroly en Colombia en donde se expone en 1925, una investigación psicolingüística sobre el aprendizaje del lenguaje en el niño ${ }^{46}$. Sin embargo, a propósito de esta visita algunos Hermanos cristianos emprendieron estudios de pedagogía activa en Bélgica.

${ }^{45}$ INSPECCIÓN NACIONAL DE EDUCACIÓN PRIMARIA Y NORMALISTA.

El Dr. Decroly en Colombia. Bogotá, Imprenta Nacional, 1932.

${ }^{46}$ LONDOÑO RAMOS, Carlos Arturo. (2001): "La escuela para la vida y por la vida: el impacto de Ovidio Decroly en la Pedagogía y la universidad colombiana". En: Revista Historia de la educación colombina. Pereira, RUDECOLOMBIA, N. 3-4. 


\section{CONCLUSIÓN}

La escuela elemental de comienzos del siglo XX apuntó a formar personas útiles al proyecto hegemónico del momento: orientación firme, corazones sumisos y generosos, obreros modelos, ciudadanos obedientes y creyentes y soldados intrépido.

Se insistió en hacer énfasis en la autoridad sobre los sentimientos, pues aquella perduraba, estos no. El buen maestro debía cumplir con unas condiciones de moral muy elevadas, dando ejemplo como lo dio Jesucristo, sembrando ideas y haciendo aceptar principios con convicciones profundas desde el orden físico, intelectual y moral.

Se consideraba que cuando en ese recinto sacro de la escuela se falseaban las nociones, entonces eran instrumento móvil de decadencia y ruina. Los elementos de una buena educación eran: Dios, los padres, el maestro, el condiscípulo y el educando.

Se aclaraba la necesidad de establecer la diferencia entre el método con el procedimiento: el método en la enseñanza era el camino que seguía el espíritu, para exponer y hacer comprender la verdad de lo que le enseñaban; el procedimiento era el medio práctico que empleaba el método para alcanzar su objetivo. Leer una frase y hacer escribir en las pizarras palabras que por las relaciones que guardaban entre sí o que contenían la regla que se pretendía aplicar y retener, y después presentar las pizarras y examinar si se había escrito bien o mal, es otro procedimiento. Los maestros debían hacer saber a sus estudiantes los respectivos métodos y procedimientos utilizados.

En cuanto a los textos escolares, estos encajaron dentro de la ideología conservadora a favor de una propuesta hispanista, de nacionalismo unitario y catolicismo. A pesar de que todos promovían una metodología activa orientada hacia el trabajo, el enfoque que dieron a conocer, tanto en su contenido, forma y estructura fue igual para todos. Estos defendieron la escolástica contemplativa y el contubernio Iglesia-Estado. Por estas razones la Iglesia prohibió el libro El Dr. Decroly en Colombia en donde se expone en 1925, una investigación psicolingüística sobre el aprendizaje del lenguaje en el niño. 


\section{FUENTES}

BRUÑO, G.M. (1887): Silabario de Lectura: curso preparatorio. Lima: Procuraduría General de los Hermanos cristianos.

CHARRY, Justo V. (1917): Enseñanza Simultánea de Lectura y Escritura: Libro 1 y Libro 2. Bogotá: editorial Voluntad (Para la edición de 1949).

COLOMBIA. MINISTERIO DE EDUCACIÓN. Educación Colombiana: 1903-1958. Bogotá: Imprenta Nacional, 1959.

CONCORDATO DE 1887, art. 11, 12, 13,14. Constitución Política de Colombia 1886, art. 41.

DIARIO OFICIAL 12.122. Decreto número 491 de 1904 (3 de junio). Jueves 14 de julio de 1904.

DIARIO OFICIAL 12.122. DECRETO 491 de 1904, art. 1 al 5 de la Ley 39 de 1903,

EVANGELISTA RENTERÍA, Quintana. (1930): Alegría de leer: grado primero. Bogotá: Editorial Voluntad, 38 edición.

GONZAGA, Luis. "Discurso pronunciado en la distribución de premios en la Escuela Normal Central de Institutores de Bogotá, el 29 de noviembre de 1913." En: Revista de Instrucción Pública de Colombia. Bogotá: Órgano del Ministerio del Ramo. N. 1 y 2, T. XXVI (enero-febrero, 1913).

GOODING DE CÁRDENAS, Eva y GOODING, Paulina. (1097): ElEscolar Hispanoamericano. Bogotá: Tipografía de Aranza.

INSPECCIÓN NACIONAL DE EDUCACIÓN PRIMARIA Y NORMALISTA. El Dr. Decroly en Colombia. Bogotá: Imprenta Nacional, 1932.

INTENDENCIA DEL META. Informe del Vicario Apostólico del Casanare, Inspector de Instrucción Pública en las escuelas de ese territorio de la Intendencia del Meta, en el primer semestre del año. Casanare. El autor, 1905.

MANTILLA, Luis Felipe. (1910): Libro de lectura, N. 2. París, Librería de la Viuda de $\mathrm{CH}$. Bouret.

MANTILLA, Luís F. Libro de Lectura 1, 2, 3. París, México: Librería de la Vda. de Ch. Bouret, 1914. 
REPÚBLICA DE COLOMBIA, MINISTERIO DE INSTRUCCIÓN PÚBLICA. Circular N. 1025.

RESOLUCIÓN NÚMERO 134 del 19 de noviembre de 1906. Por la cual se aprueba el Decreto número 87 de 1906 para su aprobación enviado al Despacho del Gobernador del Departamento del Huila y donde se reglamentan las escuelas primarias.

RESOLUCIÓN NÚMERO 134 de 1906.

SANÍN DÍAZ, Constanza y SANÍN HERRÁN Carmen. (1913): El lector colombiano: libro de lectura ideológica para el uso de las escuelas de la República. Bogotá, (s.e).

\section{REFERENCIAS}

BÁEZ OSORIO, Myriam. (2004): Las Escuelas Normales y el cambio educativo en los Estados Unidos de Colombia en el periodo Radical, 1870-1886. Tunja, Universidad Pedagógica y Tecnológica de Colombia.

CARDOSO ERLAM, Néstor Roberto. (2001): Los textos de lectura en Colombia: aproximación histórica e ideológica, 1872-1917, en Revista Educación y cultura, N. 29-30, Vol. XIII (ene-sep). Medellín, Universidad de Antioquia.

CARDOSO ERLAM, Néstor Roberto. (2007): Los textos escolares en Colombia: dispositivos ideológicos, 1870-1931. Ibagué, Universidad del Tolima.

DE LA TORRE GÓMEZ, Andrés. (2003): “El método socrático y el modelo de Hiele". Universidad de Antioquia, Medellín. En: Lecturas Matemáticas. Vol. 24.

FEBVRE, Lucien y MARTIN, Henri Jean. (2005): La aparición del libro. México, FCE.

JARAMILLO URIBE. (1980): Manual de Historia de Colombia: el proceso de educación. Bogotá, Colcultura. 
LONDOÑO RAMOS, Carlos Arturo. (1985): "El discurso reactivo de la enseñanza escolar de la filosofía”, en Revista Educación y Ciencia. Quinta época, año I. Tunja, Universidad Pedagógica y Tecnológica de Colombia.

LONDOÑO RAMOS, Carlos Arturo. (2004): "La educación en la democracia integral: el constructivismo práctico de John Dewey y el impacto pedagógico de la Escuela Nueva durante la República liberal en Colombia”, en Revista Cuestiones de filosofía. N. 6, Tunja, UPTC.

TORRES CRUZ, Doris Lilia. (2010): "Política educativa y enseñanza de la lengua castellana en la educación elemental en Colombia en las tres primeras décadas del siglo XX". Doctorado en Ciencias de la Educación, Universidad Pedagógica y Tecnológica de Colombia. RUDECOLOMBI. Tesis doctoral.

TORRES CRUZ, Doris Lilia; LONDOÑO RAMOS, Carlos Arturo. (2011): “Textos y pedagogía en los albores del siglo XX, en Colombia" en: Revista Historia de la Educación Latinoamericana N. 16, Tunja, Universidad Pedagógica y Tecnológica de Colombia, RUDECOLOMBIA, SHELA- HISULA pp. 255-278 